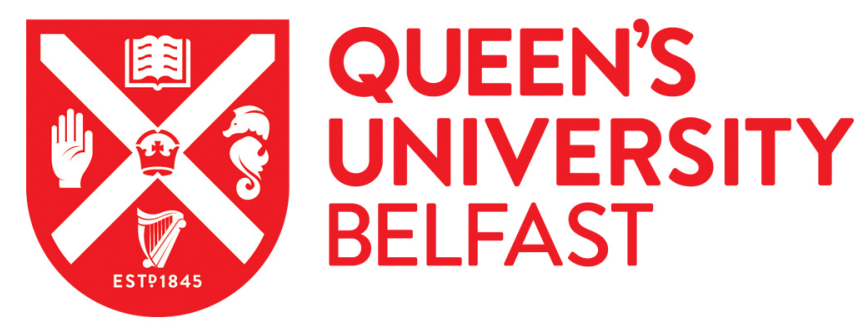

\title{
Developing pharmacist-facilitated medicines review services for community-dwelling Māori older adults in New Zealand - A qualitative study exploring stakeholder views
}

Hikaka, J., Jones, R., Hughes, C., Connolly, M. J., \& Martini, N. (2021). Developing pharmacist-facilitated medicines review services for community-dwelling Māori older adults in New Zealand - A qualitative study exploring stakeholder views. Health and Social Care in the Community, 29(2), 564-573.

https://doi.org/10.1111/hsc. 13119

\section{Published in:}

Health and Social Care in the Community

Document Version:

Peer reviewed version

Queen's University Belfast - Research Portal:

Link to publication record in Queen's University Belfast Research Portal

\section{Publisher rights}

Copyright 2020 Wiley. This work is made available online in accordance with the publisher's policies. Please refer to any applicable terms of use of the publisher.

\section{General rights}

Copyright for the publications made accessible via the Queen's University Belfast Research Portal is retained by the author(s) and / or other copyright owners and it is a condition of accessing these publications that users recognise and abide by the legal requirements associated with these rights.

Take down policy

The Research Portal is Queen's institutional repository that provides access to Queen's research output. Every effort has been made to ensure that content in the Research Portal does not infringe any person's rights, or applicable UK laws. If you discover content in the

Research Portal that you believe breaches copyright or violates any law, please contact openaccess@qub.ac.uk. 


\title{
Developing pharmacist-facilitated medicines review services for community-dwelling
}

\section{Māori older adults in New Zealand - a qualitative study exploring stakeholder views}

\begin{abstract}
Māori (Indigenous people of New Zealand (NZ)) experience inequitable health outcomes compared to non-Māori, across the spectrum of clinical care, including those relating to medicines. Internationally, pharmacist-facilitated medicines review services have been shown to benefit older adults. Despite national policies calling for the increased implementation of these services, NZ data relating to them remains limited, and these services may increase disparities between Māori and non-Māori. There are currently no medicines review services developed specifically for Māori older adults. The current study aims to elicit stakeholder views of current and potential pharmacist services to help inform the development of a pharmacist-facilitated medicines review service for communitydwelling Māori older adults.
\end{abstract}

Kaupapa Māori theory was applied within this qualitative research. Purposive sampling was used to recruit participants who were involved in providing, planning, funding, developing or culturally supporting health services in Waitematā District Health Board, Auckland, NZ. Data were collected in semi-structured interviews and in a focus group and analysed using reflexive thematic analysis. The study was reported in accordance with the Consolidated Criteria for Reporting Qualitative research (COREQ).

Eleven participants took part in the research in one focus-group $(n=4)$ and 7 semi-structured interviews, conducted between November 2018 and March 2019. Three main themes were generated: 1 . Moving out of the shadows - claiming pharmacists' unique role within a healthcare whānau (family); 2. "Give them the power to be able to ask" - upholding the 
mana (self-esteem, pride, standing) and autonomy of kaumātua (Māori older adults); 3. Rights versus realities - reimagining pro-equity Māori health services within the constraints of the colonial health system.

The right of Māori to experience equitable health outcomes needs to be included in policy and also operationalised in relation to medicines review services through improved utilisation of pharmacist skills and improving Māori older adults' autonomy and control.

Keywords: health equity, health service development, stakeholder engagement, medicines reviews, pharmacist, Māori, older adults.

\section{What is known about this topic:}

-Pharmacist-facilitated medicines reviews can improve the quality use of medicines.

- Currently these services in NZ may increase disparities in health outcomes between Mãori and non-Māori.

- It is important to engage stakeholders in the redevelopment of culturally safe, pro-equity health services.

\section{What this paper adds:}

- This paper is the first of its kind, engaging with stakeholders to support the development of pharmacy services for community-dwelling Indigenous older adults.

- It informs the theoretical framework and intervention design for a pharmacist-facilitated medicines review services for Māori older adults and other marginalised groups.

- It adds to the literature regarding Indigenous community-health services development.

\section{Introduction}


Colonisation, and its contemporary impacts across all levels of governance and infrastructure, continue to drive inequities in health outcomes in Aotearoa New Zealand (NZ)(Reid et al., 2014). These systemic inequities lead to avoidable, unfair and unjust differences in the way determinants of health (including education, employment and housing) are resourced, distributed and provided (Reid \& Robson, 2007; Robson, 2004). In the context of health, this results in Māori (Indigenous people of NZ; 15\% of the population) experiencing poorer access to and quality of care across a range of clinical contexts, compared to non-Māori (Health and Disability System Review, 2019; Health Quality \& Safety Commission, 2019). This includes inequitable access to medicines, with Māori being less likely than non-Māori to be prescribed medicines that treat and prevent long-term conditions (Metcalfe et al., 2018), whilst being more likely to be prescribed medicines which cause harm (Metcalfe et al., 2018; Nishtala et al., 2014). All these inequities contribute to a lower life expectancy for Māori, being approximately 7 years lower than that of non-Māori (Ministry of Health, 2015b).

Older adults are more likely to experience adverse events from medicines, including increased morbidity and rates of hospitalisations compared with younger people (Budnitz et al., 2006; Hamilton et al., 2011). Pharmacist-facilitated medicine reviews have been shown to improve the quality of prescribing and reduce adverse outcomes in older adults (Gray et al., 2018; Riordan et al., 2016). Medicines reviews are defined in the current paper as 'intentional, structured and critical review of medicines, carried out by health professionals, in discussion with the patient, and with the aim of agreeing on optimal medicines use to improve the quality, safety and appropriate use of medicines' (Hikaka et al., 2019a). 
In NZ, medicines review services vary in extent from simple reviews of a medicine regimen to check for drug-drug interactions and appropriate doses, to reviews focusing on adherence and education, through to comprehensive reviews with access to full clinical information and laboratory results (which may or may not include a pharmacist in a prescribing role), often in collaboration with other health professionals and the patients themselves (Pharmaceutical Society of New Zealand, 2014). The training requirements for pharmacists to deliver these services also vary and include 'on-the-job' training, short formal training courses and formal post-graduate tertiary education. The services are offered in various locations including community pharmacies, long term care facilities, patients' homes and general practices. NZ is divided geographically into 20 different District Health Boards (DHBs) which are largely responsible for managing the planning, funding and provision of health services in NZ. This includes access to and funding of pharmacistfacilitated medicines review services. The availability and funding of medicines reviews vary greatly between DHBs. The variations in service type, pharmacists' training and experience, and resourcing all have the potential to further contribute to the inequities in health outcomes seen in NZ.

Health, and access to healthcare, is a basic human right. The right of Māori to experience equitable health outcomes is further guaranteed in the Treaty of Waitangi, one of NZ's founding documents, and the basis of contemporary NZ policy (Waitangi Tribunal, 2019). Despite the legislation and policies, the health system continues to be structured in equities, and disparities in health outcomes for Māori continue (Waitangi Tribunal, 2019). National policies also identify the need for an increase in pharmacist-facilitated medicines reviews, which remain underutilised in NZ (Health and Disability System Review, 2019; Ministry of Health, 2015a, 2016). Those which currently exist in NZ may not be designed or 
implemented in a way that meets the particular needs of older adults or Māori (Hikaka et al., 2019a). They may also increase disparities in health outcomes due to inequitable access to these services for Māori and the benefit gained not being to the same extent as for nonMāori (Hikaka et al., 2019a). The right of Māori to receive medicines review and optimisation services, delivered by culturally competent practitioners in a culturally safe manner, to support the achievement of Māori health equity, has been articulated in the literature (Te Karu et al., 2018).

To develop a medicines review service intended to address inequities and support Māori wellbeing, it is important to engage all stakeholders in the discussion surrounding service development (Craig et al., 2008), with Māori leadership and involvement throughout (Health and Disability System Review, 2019; Waitangi Tribunal, 2019). This helps with the eventual implementation and potential success of service redevelopment (Craig et al., 2008). Our research group has previously reported findings from interviews with kaumātua (Māori older adults) concerning their experiences with medicines and medicine-related services (XX, 2020). The aim of the current paper is to elicit the views of those involved with the planning, funding, design and development, cultural support or provision of health services regarding the design, implementation and evaluation of pharmacist-facilitated medicines review service for community-dwelling Māori older adults. It is intended that these results will, in part, inform future service development.

Ethics approval was granted by the Northern A Health and Disability Ethics Committee, NZ $(X X)$.

\section{Methods}

Theoretical framework 
A kaupapa Māori theoretical framework was used in this qualitative research. 'Kaupapa Māori' can be translated as a 'Māori approach' or Māori ideology. Kaupapa Māori theory assumes the right of Māori to participate in healthcare service development and research, privileges Māori knowledge (Pihama, 2010), and aims for positive, transformative change for Māori (Curtis, 2016; Smith, 2012). It also examines power relationships that exist in research (and healthcare), aiming to redress the balance of power and control (Smith, 2012). This approach was chosen to examine findings in the context of Māori realities, and to challenge the bio-medical narrative which dominates the health space. As opposed to post-positivist research, kaupapa Māori research requires examination of the active position the researcher plays in the processes, shaping the entire journey (Pihama, 2010). It also requires practical application (Goodson, 2010) of this theory with a clear intent of activism (Pihama, 2010) exerting the right of Māori control and self-determination, and with decolonial intent (Pihama, 2010; Smith, 2012). Kaupapa Māori theory may be applied to mainstream 'Western' research methods (those 'conventionally accepted' in academia (Massey \& Kirk, 2015)), however, the core principles of kaupapa Māori theory must be upheld (Henry \& Pene, 2001).

\section{$\underline{\text { Recruitment and participants }}$}

Purposive sampling was used to recruit participants (identified through researcher networks). Purposive sampling is commonly used in qualitative research (Patton, 1990), including that related to health (Palinkas et al., 2015), and was specifically used in this study to better support its transformative potential and real-world application. Inclusion criteria were those working in roles within Waitematā District Health Board (WDHB; NZ's largest 
DHB servicing approximately 630,000 people $10 \%$ of which identify as Māori (Ministry of Health, 2019) involving the:

- planning, funding, design and development or health services AND/OR

- Māori cultural support of health services AND/OR

- the delivery of pharmacy services AND/OR

- provision of other health services.

Participants were initially approached through face-to-face meetings, telephone calls or email correspondence. A record was made of those that declined to participate for reporting purposes. Written, informed consent obtained by XX in a face to face meeting. The decision to be involved in either a focus group or individual interview was participantled. It was influenced by their preference for either group or confidential, individual discussion, as well as availability to partake in a group session which required flexibility and a degree of (researcher-facilitated) co-ordination and with others. Recruitment stopped when there were at least three participants from each of the inclusion criteria groups, noting that some participants may hold multiple roles.

This study took a pragmatic approach and aimed to include multiple people at various stages of the funding, planning and provision of medicines-related services in WDHB, which informed the development of the inclusion criteria and number of recruited participants. This delivered a wide range of views from those that both deliver care, and have the ability to change the provision of care to Māori older adults, as well as working within the available resources of both participants and researchers. This pragmatic approach aligns with the kaupapa Māori theoretical approach where transformational change is one of the intended 
outcomes (Smith, 2012). It also allowed for the inclusion of those whose voices would be captured in real-world medicines-related service development.

\section{Data collection}

Data were collected by XX, a Māori researcher, who facilitated a focus group and semistructured interviews which were audio recorded with participant consent. The development of connections is an important part of kaupapa Māori research and this was facilitated at this stage by: allowing time at the beginning of the interview/focus group to get to know each other, the provision of drink and food during the session, the sharing of stories and prayer (as appropriate; participant-led) to begin and conclude the session. In addition, although an estimated session duration was given to participants, the researcher had allowed time for this to extend beyond the estimated time, if directed by participants. A topic guide containing open-ended questions was developed, informed by kaupapa Māori theory (questions relating particularly to responsiveness to Māori) and the United Kingdom Medical Research Council's guidance document on complex intervention development and evaluation (Craig et al., 2008). The topics were: experience of working with pharmacies/pharmacists and Māori older adults; experience with medicine review services; thoughts on future development of medicines review service for Māori older adults; and measures of service success. Focus groups and interviews were conducted in a place convenient to participants.

\section{Data analysis}

Audio recordings were transcribed verbatim by XX, then checked for accuracy. Participants were given the opportunity to review transcripts to check for accuracy and were also supplied with a brief summary of their individual focus group/interview. Transcripts were 
entered into the qualitative data analysis software NVivo 12 (QSR International Pty Ltd. Version 12, 2018). The data were analysed using reflexive thematic analysis (Braun \& Clarke, 2006), a six-phase process (Terry et al., 2017), where inductive code generation occurs throughout the analysis process. Reflexive thematic analysis requires the application of theory although the particular type of theory is not prescribed (Braun \& Clarke, 2006). In this case kaupapa Māori theory was used in the analysis and reporting to centre the results in their wider cultural, social and political contexts. Interview transcripts were read to encourage familiarisation, then coded by XX over a period of weeks. Codes were grouped to generate themes (items of shared meaning with a "central organising concept" (Braun \& Clarke, 2019)). Thematic maps were prepared and the 'evidence' (transcripts) was reviewed with $B B$ and $A A$ to ensure the grouped codes captured distinct yet connected meaning. The themes were then named and defined. Quotes included in this paper are inserted verbatim except for where square brackets '[ ]' have been used to indicate where words have been modified to clarify the topic or content, or to replace the name of a person or practice in order to protect the identity of participants.

The study was reported in accordance with the Consolidated Criteria for Reporting Qualitative research (COREQ) (Tong et al., 2007).

\section{Positionality}

Analysis was led by XX, a Māori pharmacist who has provided medicines review services as part of primary and secondary care multidisciplinary teams as a WDHB employee for over 15 years. Participants' knowledge of XX as a pharmacist is relevant to the context of some quotes. She lives in and utilises health services within WDHB, and supported her grandparents with health system navigation and medicines management as they aged. 
These experiences have influenced all stages of the research including the larger research project which aims to improve medicines-related services for Māori older adults, the study aim and questions asked to participants through the research and interpretation of results. Being an 'insider' in this research also meant XX was able to utilise current relationships to support recruitment.

\section{Results}

A total of 11 participants took part in the research; one focus group $(n=4 ; 120$ minutes duration) and semi-structured interviews ( $n=7 ; 57$ minutes median duration (21-104 minutes)) were conducted between November 2018 and March 2019. All those approached consented to participate with the following exception: managers at two general practices were approached, requesting that general practitioners (GPs) within their practice be informed and given the opportunity to participate. These requests were declined by the managers due to GP workload.

The participants' place of work was used as the interview location in all but one case. No participants dropped out or withdrew consent. Participants ranged in age from 30-82 years (median age band was 50-60 years) and seven participants (64\%) were male. The ethnicity of participants was Māori $(n=6)$, Asian $(n=1)$, Indian $(n=1)$ and NZ European $(n=3)$. Health practitioner participants included pharmacists $(n=3)$, nurses $(n=2), \operatorname{GPs}(n=2)$ and one social worker. Other participants included those involved in the development and contracting of services (including those relevant to pharmacy and those relevant to Māori) and in the support of Māori cultural practices within the DHB. Some participants were both a health practitioner and involved in development and contracting $(n=4)$. All but one participant had 
experience in both primary and secondary care. Further specification of roles and designations is not provided in order to protect the identity of participants.

Three themes were generated in the analysis process: 1 . Moving out of the shadows claiming pharmacists' unique role within a healthcare whānau (family); 2. "Give them the power to be able to ask" - upholding the mana (self-esteem, pride, standing) and autonomy of kaumātua; 3. Rights versus realities - reimagining pro-equity Māori health services within the constraints of the colonial health system.

\section{Moving out of the shadows - claiming pharmacists' unique role within a healthcare whānau (family)}

This theme identified the importance of pharmacists in their role as medicines specialists, a role which participants felt remains unclaimed by pharmacists and poorly embedded within healthcare delivery frameworks. Participants identified factors such as the perception of pharmacists as mere suppliers of medicines, and a lack of relevant skills and training for some pharmacists, as further entrenching the underutilisation of pharmacists. Participants discussed that this unique role needs to be carried out within a connected healthcare team that operates more like a whānau (family), which comes with intrinsic values and responsibilities such as long-term commitment and relationship development.

Participants all commented that pharmacists can play a unique and important part as medicines experts in the healthcare team. They recognised that this role supported functions and roles that other members of this team held, rather than it being in place of others' roles. When pharmacists were acting in this role it freed up other clinicians to undertake their own specialist roles: 
have the appropriate knowledge and skills to deliver medicines optimisation. (Health practitioner and DHB stakeholder, non-Māori)

I truly believe that we have different roles and we need to work in as a team and what the GP does is a diagnostician, that's their expertise. [Pharmacists] are the experts in medicines, far more than I will ever be. I just don't have the time for that... But people get so blurred and they think they all have to do everything. (Health practitioner and DHB stakeholder, Māori)

Participants noted that the lack of appropriate funding and an overall structure which silos pharmacies and pharmacist services, further prevented pharmacists claiming the medicines expert role and providing clinically appropriate care. Also, participants noted that when it came to providing the best care to Māori specifically, that pharmacists need to have culturally appropriate education and training:

...the existing [pharmacy] workforce need to have the capabilities to meet the needs of Māori. (Health practitioner and DHB stakeholder, non-Māori)

The image of pharmacists solely as medicine suppliers was also seen as a barrier to pharmacists operating as medicines experts within a healthcare team:

You guys, first off, have got to move out of the shadow of the docs... and hold your own mana... (Health practitioner and DHB stakeholder, Māori)

Participants reflected on the 'lost opportunities' both to the pharmacy profession and kaumātua when pharmacists did not provide health support at the point of medicines supply. The need for pharmacists to move past the traditional dispensing roles and claim their unique roles within the healthcare team for the benefit of kaumātua was identified. Participants talked about the concept of pharmacists as part of a healthcare whānau (family). Compared to the use of the term healthcare 'team', it draws on values intrinsic within familial workings and changes the methods used to approach and evaluate engagement: 
I want our pharmacist with our kaumàtua - in a lot of ways - to be not only that knowledgeable wonderful person that goes there, but part of our health whannau (Health practitioner and DHB stakeholder, Māori)

\section{"Give them the power to be able to ask" - upholding the mana and autonomy of kaumātua}

This theme recognised the knowledge kaumātua hold - in relation to their medicines as well as more widely - and centres on privileging and respecting kaumātua. Participants identified that pharmacists need to provide appropriate information to empower kaumātua in a way that upholds their mana as Māori, and as older adults. To do this, pharmacists need to be providing culturally safe care with an understanding of the contextual reality of Māori older adults in contemporary society:

It's our job to impart that information and to give that mana to the whannau (family). It's their mana, not ours to take. (Health practitioner and DHB stakeholder, Māori)

Participants discussed that kaumātua are the ones that know the most about their own health and wellbeing and that when services are developed and delivered, they need to be done in a way that acknowledges this, empowers them to maintain this control, and be relevant to their position as Māori older adults:

They know their bodies so well. They know what works; they know what doesn't work... And we just talk about, that those are the evolving changes that they have, and they get it. (Health practitioner and DHB stakeholder, Māori)

Participants described ways in which the mana of kaumātua could be upheld by changing the narrative. One participant described this by discussing that when pharmacists talk to kaumātua about their medicines there should be "no assumption that they are getting it wrong", highlighting that dominant discourse often places blame on individual patients if medicines are taken in a different way to what has been prescribed. 
Participants discussed ways in which these responsibilities could be enacted including the empowerment of kaumātua by pharmacists through the development of an equal, reciprocal relationship to enable active participation in medicines-related conversations: ...giving [kaumātua] the power to be able to ask, because it's that power relationship [between clinician and kaumātua] that's really bad. (Health practitioner and DHB stakeholder, Māori)

Participants also saw the inclusion of kaumātua in the development of service models as a critical part in the empowerment process:

The ultimate is that the consumers are empowered to design the solution with you, alongside the health service... They don't want the tick box; they want to see that they are part of the solution that you're putting together.... (DHB stakeholder, nonMāori)

\section{Rights versus realities - reimagining pro-equity Māori health services within the constraints of the colonial health system}

This theme highlighted participants' recognition that although the health system and health practitioners have responsibilities to provide equitable care under the Treaty of Waitangi, tensions exist in the development and evaluation of transformative, pro-equity services within the constraints and drivers of NZ's colonial healthcare system.

Participants talked of the need to hold the health system accountable for the current inequities in health outcomes for Māori. Current services, with their 'one-size-fits-all approach', are not designed to protect the right of Māori, with any Māori 'success' or good health happening by chance rather than design:

One thing we struggle with is at the moment, particularly in community pharmacy, is that it's a one size fits all, basically, so how you get community pharmacy to have their services be more responsive to where there is greater need such as kaumatua is something where, obviously, that's a real challenge. (DHB stakeholder, non-Māori) 
By luck [Māori] may get good care but it's definitely not aimed towards them, and it should be. (Health practitioner and DHB stakeholder, Māori)

Although participants recognised that health service development and delivery need to change, there was variation in the way participants felt the change should be approached. Some felt that complete overhaul was needed, while others discussed that the development of medicines review services for kaumātua required 'tweaking' the current system and was associated with difficulties:

It can be quite challenging when we have a system that looks at the entire population. And trying to design services that meet the requirements of that full population and not really thinking about what are the specific needs that might be different in those high need, priority groups. (Health practitioner and DHB stakeholder, non-Māori)

When you have an infrastructure out there that already has trouble working effectively and efficiently, and then you say "look, we want to focus specifically on high needs group". How do we manage to coax as much out of the system that doesn't work as well as it could do? (Health practitioner and DHB stakeholder, nonMāori)

Participants discussed that kaumātua satisfaction needed to be privileged when evaluating service success (or otherwise). There were some other, varied outcomes discussed by participants. These were reflective of their own experiences, world views and the professional roles they had. Relevant to this was the discussed need for multiple stakeholders' expectations to be met for wider implementation, uptake and resourcing:

We would want to measure some clinical outcomes, hospitalisations, frequency of visits to GPs. We may want to look at some disease specific indicators... (Health practitioner and DHB stakeholder, non-Māori)

One participant discussed that outcome measures used in the current health system were often formulaic. She described that her clinical experience and understanding of impact or success may be difficult to measure in a tangible way: 
If I can make a difference, somewhere, then I'm really, really happy. And I don't have a box to tick as such but my heart is like "Yes! It's a win!" So, my soul is elated. (Health practitioner and DHB stakeholder, Māori)

Participants discussed that financial resourcing was the major driver of any health service and the conflict between the rights of Māori and the realities within the current health system were apparent:

We're Māori working in a very non-Maori institution, they have the purse strings (Health practitioner and DHB stakeholder, Māori)

Understanding the (current) business model is really important as you can come up with the best idea in the world but, if it doesn't make financial sense, it's not going to happen. (Health practitioner and DHB stakeholder, non-Māori)

\section{Discussion}

The themes in this study were all connected by the concept that successful service provision for Māori needed reworking of the system in a way that effectively utilised the unique and important skills of multiple stakeholders, including kaumātua themselves.

Identifying the need to improve utilisation of pharmacists in medicines management roles is supported in recent national reports and strategies (Health and Disability System Review, 2019; Ministry of Health, 2016), There are currently barriers in infrastructure in NZ which limit this type of work, for example, the majority of pharmacists work in community pharmacy, without access to in-depth clinical patient information, preventing pharmacists' ability to apply clinically-informed reasoning to the provision of medicines information.

Our previous research identified that although kaumātua sought authentic healthcare partnerships with pharmacists to support their own medicines knowledge, they experienced pharmacist services as a business transaction, devoid of a wider provision of healthcare $(X X, 2020)$. This 'dichotomy' between the role of pharmacist retailer and that of a health 
professional is well recognised in the pharmacy profession (Scahill et al., 2018) Participants discussed the term 'healthcare whānau (family)' which supports the development of relationships that extend beyond that of business retailer. Using the term healthcare whānau values the different ways in which members contribute to the whānau, and that the whānau would not be 'whole' without the various members. It incorporates the notion that relationships will be developed and sustained over time. The concept of 'whānau' in healthcare partnerships parallels ways of working within kaupapa Māori research (Smith, 2012) in relation to accountability, multiple roles and long-term commitment. An important aspect of authentic partnership with kaumātua is the provision of culturally safe care, and expectation of all health practitioners in NZ (Health Quality \& Safety Commission, 2019; Waitangi Tribunal, 2019). Understanding power imbalances and implementing strategies to recognise and address these are key aspects of providing culturally safe care. Equal, authentic partnership is a key principle of the Treaty of Waitangi (one of NZ's founding documents), one which has been breached, contributing to health inequities seen in contemporary NZ society (Waitangi Tribunal, 2019). Redressing the normalised power imbalance in the planning and delivery of health services is vital to delivering culturally safe care and achieving Māori health equity (Curtis et al., 2019).

The need for pharmacists to give kaumātua respect was a major finding of this research. In Māori society, kaumātua are regarded as having a special standing associated with the knowledge they hold, accumulated over the life course. This is in contrast to contemporary Western society where older adults are often described in terms of the associated burden to society rather than the value they can provide (Durie, 2009). Participants discussed that often it is assumed that kaumātua are 'getting it wrong' when it comes to their medicines use. This assumption has been noted in wider literature when it comes to Māori (Penney et 
al., 2011) and also older adults, however, often this results from 'intelligent non-compliance' where patients change medicine regimens themselves to balance therapeutic and adverse effects, resulting in improved outcomes (Weintraub, 1981). Participants argued that kaumātua want to take control and understand their medicines, and that pharmacists need to support this, important findings for future service development.

Many participants, although in theory acknowledged the need to prioritise Māori health equity, demonstrated limited understanding of how to do this practically. This mirrors the dissonance between national health policy relating to health equity, and the practical application of these policies that exist in NZ and internationally (Chin et al., 2018). Renormalising the right of Māori to experience equitable health, and developing services to enact transformative change is difficult within the current constraints of the Western health system that is developed 'by the majority, for the majority'. The need for explicit intent in the development of pro-equity services has been discussed both nationally (Health Quality \& Safety Commission, 2019; Waitangi Tribunal, 2019) and internationally (Chin et al., 2018). Although some participants discussed the need for creating change within the current system, several NZ reviews have called on the need for multi-level, systemic health sector reform to create transformative change(Health and Disability System Review, 2019; Waitangi Tribunal, 2019), including the establishment of a new, independent Māori health authority (Waitangi Tribunal, 2019).

Despite their theoretical acknowledgement that health inequities for Māori need to be addressed, there was the general assertion that decisions about new or revised health service provision still had to make 'business' or 'financial' sense, otherwise the reality was that the service would not go ahead. This approach to health service development and 
delivery is entrenched NZ's health system in which Māori are worse off due to the differential resource allocation (Robson, 2004). It also fails to recognise the 'value' of Māori health equity in the equation. The existence of institutional racism within public health contracting in NZ has previously been reported, with Māori health providers being subject to more frequent and intense monitoring, shorter contract lengths and higher compliance costs, than mainstream services (Came et al., 2018). This reality gives further weight to the argument for an independent Māori health authority, driven by the right of Māori to thrive, flourish and experience health equity, that builds financial resourcing around this right.

\section{Strengths and limitations}

A strength of the current study is the approach to identify and include participants with the ability to influence health service development within WDHB. Understanding the experiences and views of these participants allows for the pragmatic design and evaluation of a medicines review service with the potential for it to work in 'real-life', an aspect essential in kaupapa Māori research. Understanding both the differences and commonalities between the participants is important when working in developing health services where there are multiple stakeholders involved. It allows for an understanding of common goals and drivers, whilst also potential barriers that need to be overcome to deliver an effective service. Utilising kaupapa Māori research approaches is another strength as services developed using these approaches have been shown to improve Māori outcomes (Carlson et al., 2019; Kerr et al., 2010).

A mixture of focus groups and individual interviews were used for data collection. Focus groups were used to encourage collective thought generation. Semi-structured interviews were used in addition to the focus groups to allow participation from those who preferred 
not to discuss ideas in a 'public' forum, potentially leading to more in-depth discussion. Oneon-one interviews also increased accessibility to participants as they allowed greater flexibility with interview time by not relying on the availability of others and a shorter time commitment from participants.

The focus on stakeholders from WDHB alone, the largest DHB in NZ, and the relatively small sample size of 11 , limits the generalisability of results. However, it was relevant to the pragmatic approach taken in this research, with the ultimate aim of developing a medicines review service for Māori older adults in WDHB. The methods utilised and the situating of the results within the broader context of national policy and Indigenous health inequities are of importance and relevance to a wide audience.

The lack of an independent facilitator/ interviewer may be seen as a limitation. The facilitator/interviewer was known to most of the participants prior to this study and all knew at the point of interview that she was a pharmacist with the goal of developing medicines review services for community-dwelling Māori older adults. This may have influenced how participants responded to some questions. However, insider knowledge of the issues and the sector (pharmacy services, Māori health, older adult medicine), as well as relevant skills, were important for the semi-structured nature of the focus groups/interviews that facilitator/interviewer; the reality is that this resource is extremely limited. As discussed, there are both advantages and disadvantages to the approach taken in this current study which have been well documented previously (Greene, 2014). Purposive sampling may be seen as a potential limitation of this study, however, given the pragmatic considerations of developing a real-world service, it was useful to have participants with the ability to support potential change in service delivery. 
The results reported in this paper present one set of perspectives relevant to future service development. In addition to the findings from this study, our group has undertaken a systematic review (XX, 2019) and qualitative study with Māori older adults (XX, 2020) to develop an intervention which is currently being tested in a feasibility study (XX, 2019a) further highlighting the transformative potential of this work.

\section{Implications for service development}

The themes identified in this paper allow us to draw out some practical aspects which can be used, in part, to inform the development of pharmacist-facilitated medicines review services for kaumātua. Any service model developed needs to ensure pharmacists delivering the service have the clinical training and experience to be seen as a 'medicines expert' both by patients and other clinicians. The delivery of the service needs to happen as part of the patients' wider healthcare team and there needs to be robust, two-way communication between the different members of the team, which includes the kaumātua. The service model needs to be culturally safe and enable kaumātua to make decisions, not only about their medicines but how the intervention is delivered, which will give power to the kaumātua. The intended outcomes of the service will need to be defined prior to development and delivery of the intervention to ensure any conflicts in expectations between the multiple stakeholders are clarified from the outset. This also allows a proequity response to be centred from the outset and defined as non-negotiable.

\section{Conclusion}

This paper reports on the views of health practitioners and commissioners of services concerning the development of medicines review services for Māori older adults in NZ. Participants discussed the need for pharmacists to claim their role as medicines experts and 
uphold the rights, power and autonomy of Māori older adults in the process. The ability to develop transformative services within the constructs of the current health system in NZ was discussed, including the need to satisfy factors important to multiple stakeholders, and in the context of the right of Māori to experience equitable healthcare. The right of Māori to experience equitable health outcomes needs to not only be included in policy but also operationalised in relation to medicines review services through improved utilisation of pharmacist skills and improving Māori older adults' autonomy and control. These findings are of relevance to those involved in the development and delivery of equitable health services and health policy within NZ and internationally.

List of abbreviations: NZ = Aotearoa New Zealand; WDHB = Waitematā District Health Board; DHB = District Health Board; GP = general practitioner.

\section{References}

Braun, V., \& Clarke, V. (2006). Using thematic analysis in psychology. Qualitative Research in Psychology, 3(2), 77-101. https://doi.org/10.1191/1478088706qp063oa

Braun, V., \& Clarke, V. (2019). Reflecting on reflexive thematic analysis. Qualitative Research in Sport, Exercise and Health, 11(4), 589-597. https://doi.org/10.1080/2159676X.2019.1628806

Budnitz, D. S., Pollock, D. A., Weidenbach, K. N., Mendelsohn, A. B., Schroeder, T. J., \& Annest, J. L. (2006). National surveillance of emergency department visits for outpatient adverse drug events. Jama, 296(15), 1858-1866.

Came, H., Doole, C., McKenna, B., \& McCreanor, T. (2018). Institutional racism in public health contracting: Findings of a nationwide survey from New Zealand. Social Science \& Medicine, 199, 132-139. https://doi.org/10.1016/j.socscimed.2017.06.002 
Carlson, T., Moewaka Barnes, H., \& McCreanor, T. (2019). Health literacy in action: Kaupapa Māori evaluation of a cardiovascular disease medications health literacy intervention. AlterNative: An International Journal of Indigenous Peoples, 15(2), 101110. https://doi.org/10.1177/1177180119828050

Chin, M. H., King, P. T., Jones, R. G., Jones, B., Ameratunga, S. N., Muramatsu, N., \& Derrett, S. (2018). Lessons for achieving health equity comparing Aotearoa/New Zealand and the United States. Health Policy, 122(8), 837-853. https://doi.org/10.1016/j.healthpol.2018.05.001

Craig, P., Dieppe, P., Macintyre, S., Michie, S., Nazareth, I., Petticrew, M., \& Medical Research Council Guidance. (2008). Developing and evaluating complex interventions: The new Medical Research Council guidance. British Medical Journal, 337, a1655.

Curtis, E. (2016). Indigenous positioning in health research: The importance of Kaupapa Māori theory-informed practice. AlterNative: An International Journal of Indigenous Peoples, 12(4), 396-410.

Curtis, E., Jones, R., Tipene-Leach, D., Walker, C., Loring, B., Paine, S.-J., \& Reid, P. (2019). Why cultural safety rather than cultural competency is required to achieve health equity: A literature review and recommended definition. International Journal for Equity in Health, 18(1), 174. https://doi.org/10.1186/s12939-019-1082-3

Durie, M. (2009). Impacts of an Ageing Population on New Zealand Society. In Nga tini whetu: Navigating Maori futures. Huia Publishers.

Goodson, P. (2010). Theory in Health Promotion Research and Practice: Thinking outside the box. Jones \& Bartlett Publishers. 
Gray, S. L., Hart, L. A., Perera, S., Semla, T. P., Schmader, K. E., \& Hanlon, J. T. (2018). Metaanalysis of Interventions to Reduce Adverse Drug Reactions in Older Adults. Journal of the American Geriatrics Society, 66(2), 282-288.

Greene, M. J. (2014). On the inside looking in: Methodological insights and challenges in conducting qualitative insider research. The Qualitative REport, 19(29). http://nsuworks.nova.edu/tqr/vol19/iss29/3

Hamilton, H., Gallagher, P., Ryan, C., Byrne, S., \& O’Mahony, D. (2011). Potentially inappropriate medications defined by STOPP criteria and the risk of adverse drug events in older hospitalized patients. Archives of Internal Medicine, 171(11), 10131019.

Health and Disability System Review. (2019). Health and Disability System Review: Interim report. Hauora manaaki ki Aotearoa whānui-Pūrongo mō tēnei wā. (p. 312). HDSR. Health Quality \& Safety Commission. (2019). A window on the quality of Aotearoa New Zealand's health care 2019. Health Quality \& Safety Commission.

Henry, E., \& Pene, H. (2001). Kaupapa Maori: Locating Indigenous Ontology, Epistemology and Methodology in the Academy. Organization, 8(2), 234-242. https://doi.org/10.1177/1350508401082009

Hikaka, J., Hughes, C., Jones, R., Connolly, M. J., \& Martini, N. (2019a). A systematic review of pharmacist-led medicines review services in New Zealand - is there equity for Māori older adults? Research in Social and Administrative Pharmacy, 15(12), 13831394. https://doi.org/10.1016/j.sapharm.2019.01.009

Hikaka, J., Hughes, C., Jones, R. G., Connolly, M. J., \& Martini, N. (2019b). A pharmacist-led medicines review intervention in community-dwelling Māori older adults- a 
feasibility study protocol. Research in Social and Administrative Pharmacy.

https://doi.org/Doi:10.1016/j.sapharm.2019.12.004 [Epub ahead of print]

Hikaka, J., Jones, R. G., Hughes, C. M., \& Martini, N. (n.d.). "It is through shared conversation, that I understand"-Māori older adults' experiences of medicines and related services in Aotearoa New Zealand.

Kerr, S., Penney, L., Barnes, H. M., \& McCreanor, T. (2010). Kaupapa Maori Action Research to improve heart disease services in Aotearoa, New Zealand. Ethnicity \& Health, 15(1), 15-31. https://doi.org/10.1080/13557850903374476

Massey, A., \& Kirk, R. (2015). Bridging Indigenous and Western Sciences: Research Methodologies for Traditional, Complementary, and Alternative Medicine Systems. SAGE Open, 5(3), 2158244015597726. https://doi.org/10.1177/2158244015597726

Metcalfe, S., Beyene, K., Urlich, J., Jones, R., Proffitt, C., Harrison, J., \& Andrews, A. (2018). Te Wero tonu-The challenge continues: Māori access to medicines 2006/072012/13 update. New Zealand Medical Journal, 131(1485).

Ministry of Health. (2015a). Implementing Medicines New Zealand 2015 to 2020. Ministry of Health.

Ministry of Health. (2015b). Tatau Kahakura: Māori Health Chart Book 2015 (3rd ed.). Wellington: Ministry of Health.

Ministry of Health. (2016). Pharmacy action plan 2016 to 2020. Ministry of Health. https://www.health.govt.nz/system/files/documents/publications/pharmacy-actionplan-2016-to-2020.pdf

Ministry of Health. (2019). Population of Waitematā DHB. Ministry of Health NZ. https://www.health.govt.nz/new-zealand-health-system/my-dhb/waitematadhb/population-waitemata-dhb 
Nishtala, P. S., Narayan, S. W., Wang, T., \& Hilmer, S. N. (2014). Associations of drug burden index with falls, general practitioner visits, and mortality in older people. Pharmacoepidemiology and Drug Safety, 23(7), 753-758.

Palinkas, L. A., Horwitz, S. M., Green, C. A., Wisdom, J. P., Duan, N., \& Hoagwood, K. (2015). Purposeful sampling for qualitative data collection and analysis in mixed method implementation research. Administration and Policy in Mental Health, 42(5), 533544. https://doi.org/10.1007/s10488-013-0528-y

Patton, M. (1990). Qualitative evaluation and research methods (2nd ed.). SAGE Publications, Inc.

Pharmaceutical Society of New Zealand. (2014). New Zealand National Pharmacist Services Framework 2014.

Pihama, L. (2010). Kaupapa Māori theory: Transforming theory in Aotearoa. He Pukenga Korero, 9(2), 5-14.

Reid, J., Taylor-Moore, K., \& Varona, G. (2014). Towards a Social-Structural Model for Understanding Current Disparities in Maori Health and Well-Being. Journal of Loss and Trauma, 19(6), 514-536. https://doi.org/10.1080/15325024.2013.809295

Reid, P., \& Robson, B. (2007). Understanding health inequities. In Hauora, Māori standards of health IV. A study of the years, 2000-2005. Te Rōpū Rangahau Hauora a Eru Pōmare.

Riordan, D. O., Walsh, K. A., Galvin, R., Sinnott, C., Kearney, P. M., \& Byrne, S. (2016). The effect of pharmacist-led interventions in optimising prescribing in older adults in primary care: A systematic review. SAGE Open Medicine, 4, 1-18.

Robson, B. (2004). Economic Determinants of Māori Health and Disparities: A review for Te Rōpū Tohutohu i te Hauora Tūmatanui (Public Health Advisory Committee of the 
National Health Committee). Te Ropu Rangahau Hauora a Eru Pomare, University of Otago.

Scahill, S. L., Tracey, M. S., Sayers, J. G., \& Warren, L. (2018). Being healthcare provider and retailer: Perceiving and managing tensions in community pharmacy. Journal of Pharmacy Practice and Research, 48(3), 251-261. https://doi.org/10.1002/jppr.1410 Smith, L. T. (2012). Decolonising methodologies: Research and indigenous peoples (2nd ed.). Zed Books.

Te Karu, L., Bryant, L., Harwood, M., \& Arroll, B. (2018). Achieving health equity in Aotearoa New Zealand: The contribution of medicines optimisation. Journal of Primary Health Care, 10(1), 5 .

Terry, G., Hayfield, N., Clarke, V., \& Braun, V. (2017). Thematic Analysis. In The SAGE Handbook of Qualitative Research in Psychology (2nd ed.). SAGE Publications Ltd. https://doi.org/10.4135/9781526405555

Tong, A., Sainsbury, P., \& Craig, J. (2007). Consolidated criteria for reporting qualitative research (COREQ): A 32-item checklist for interviews and focus groups. International Journal for Quality in Health Care, 19(6), 349-357.

https://doi.org/10.1093/intqhc/mzm042

Waitangi Tribunal. (2019). Hauora-Report on Stage One of the Health Services and Outcomes Kaupapa Inquiry. Wai 2575. Waitangi Tribunal.

Weintraub, M. (1981). Intelligent noncompliance with special emphasis on the elderly. Contemporary Pharmacy Practice, 4(1), 8-11. 